\title{
PATHOLOGICAL CONTRIBUTIONS ON THE COURSE OF THE OPTIC NERVE FIBRES IN THE BRAIN.
}

\author{
BY J. DRESCHFELD, M.D., M.R.O.P.
}

Benior Aariatant Phyoioian, Manchator Royal Infirmary; Profoseor of Pathology, Fictoria Univorrity (Onoens College).

WITH the advance made in the study of cerebrul localisation the question as to the total or partial decussation of the optic nerves in the chiasma, their further course in the tract and within the brain, and their connection with a visual centre situated in the cortex of the brain, hes again come to the fore, and been made the subject of numerous observations and investigations.

The subject has been studied anatomically, by tracing the course of the fibres, and their connection with the cerebral ganglia and with the corter; it has been studied experimentally on animals in various ways; and lastly, we have the clinical observations and the study of the lesions found after death in such cases.

Of all these different lines of investigation the clinical observations and the pathological revelations have, so far, given the most concordant results, and, while I hope shortly to consider the whole subject, in reference to these several lines of research, I wish merely in this short notice briefly to describe two cases, with post-mortem results, which have an important bearing on this subject.

The history of the first case is pertially giren in the 'British Medical Journal,' Aug. 7th, 1880; the patient has since then died, and I am now enabled to give the whole history of the case, with the results of the post-mortem examination, which entirely confirmed the diagnosis made intra vitam.

The patient was seen by me for the first time on April 3rd, 1880, at the Convalescent Hospital at Cheadle, when the following notes were taken by Mr. Stanwell, then resident Clinical Clerk.

History.-N. H., aged 40, joiner, married, with no history 
of syphilis, gout, rheumatism, or alcoholic excesses, hud been ill for two years, and unable to work during the last eightoen months, suffering from giddiness, headache, double vision, with numbness, weakness and trembling of the left side. He had not suffered from romiting. The bladder and rectum had not been affected. A week before admission, he had one morning before rising three fits of distinctly epileptic character; his memory had recently become impaired, and he suffered from occasional attacks of headache, associated with febrile symptoms.

State on admission.-The patient is atrongly built, sallow, fairly nourished; he has an anxious expression, and a hesitating manner. The left side of forehead is relatively smooth, while the right side is habitually wrinkled; the left palpebral fissure is slightly the larger (he can, however, close the left eye). The left angle of the mouth is rather lower than the right; the movements of the left side of the face are less extensive. The left upper limb is colder and paler, and the left forearm measures a quarter of an inch less in circumference than the right. The grip of the left hand is weaker, and the whole limb is involuntarily and frequently jerked about. These spasmodic movements affect the forearm and arm, but not the hand or the fingers; they are incrensed by effort or attention, and especially when any movement is attempted by the right hand (as in writing) or- by any reflex excitement of the right side (such as tickling the right foot). The movements cense during sleep. The left leg is weaker than the right; it also is the seat of involuntary spasmodic movements, less in extent, but of the same character as in the left arm, and equally increased by exciting reflex contractions. The patient can walk, but in doing so drags the left leg. The patellar tendon reflex is considerably increased on the right side in both upper and lower extremities. The electric contractility is normal on both sides.

Sensation.-There is totrl left hemianæsthesin, exact III extent, both before and behind; the sensibility to contact, to pain, and to temperature being much diminished. The muscular sense is normal on the left side, and the patient distinguishes well different weights supported on the left hand; he can stand and walk with closed oyes. The pinpunctures bleed equally on the left "as on the right side. The pupils are equal and active. There is no nystagmus or ocular palsy, but there is exact and total left hemianopsia of ench field of vision. (The term "hemianopsia" is used, as Hirschberg proposed, and Mauthner and others have since adopted it, to relate to the absent field of vision, applying the term hemiopia for the insensible part of the retina-the patient 
suffered, therefore, from homonymous left hemianopsia or right homonymous hemiopia). The central vision is normal; the fundi are normal; the veins of the fundus somewhat large, those in the left somewhat tortuous. Smell and taste are normal. The ticking of a watch is heard only when the watch is in contact with either ear (the deafness is, however, of old dute). The urine is normal.

Diagnosis.-The symptoms of the case were so typical ana well-marked, and corresponded so well with what had been seen in other cases, published, with post-mortem accounts, by Gower, Hughlings-Jackson, Hirschberg, and nyself, that the case was looked upon as one of organic lesion, most likely a tumour, implicating the thalamus, the posterior part of the internal capsule, and the optic tract of the right side of the brain.

Progress.-The further progress of the case is chiefly interesting on account of the influence of the electro-magnet, the repeated application of which produced a permanent amelioration of the anosthesia, especially of the left arm and neck, without, however, in any way interfering, even temporarily, with the hemianopsia. (For a further account of this stage in the history of the cuse I may refer to the account in the "British Medical Journal 'above quoted.) During the further progress of the case, there was chiefly noticed an impairment of the mental condition of the patient; he wandered about the wards at night, disturbed the rest of the patients, and was therefore remored to the Manchester Infirmary on May 26th. For a short time he remained in the same condition. Soon, however, his mental condition became worse; he became delirious and at times violent; the hemiparesis also became worse, so that he was almost completely hemiplegic; the involuntary movements ceased, the hemianopsia remained the same, and the hemianæsthesia (as far as the patient's condition would allow an opinion to be formed) remained in the same improved condition in which we found it after the repeated application of the electro-magnet. The patient gradually grew weaker, and died on Sept. 5, 1880.

The further symptoms which had been observed during his stay in the Infirmary (namely the gradually increasing weakness of the left arm and legs, the cessation of the involuntary movements and the appearance of the mental disturbances) were believed to be due to an extension of the tumour forward, implicating more of the motor tract in the internal capsule, and to softening in the neighbourhood of the tumour.

The post-mortem examination was made by Mr. A. H. Young, Pathologist to the Infirmary, to whom I am also indebted for the accompanying sketch (Fig. 1). All the organs except the 
brain were firm and healthy, and here again the right hemisphere only was found affected.

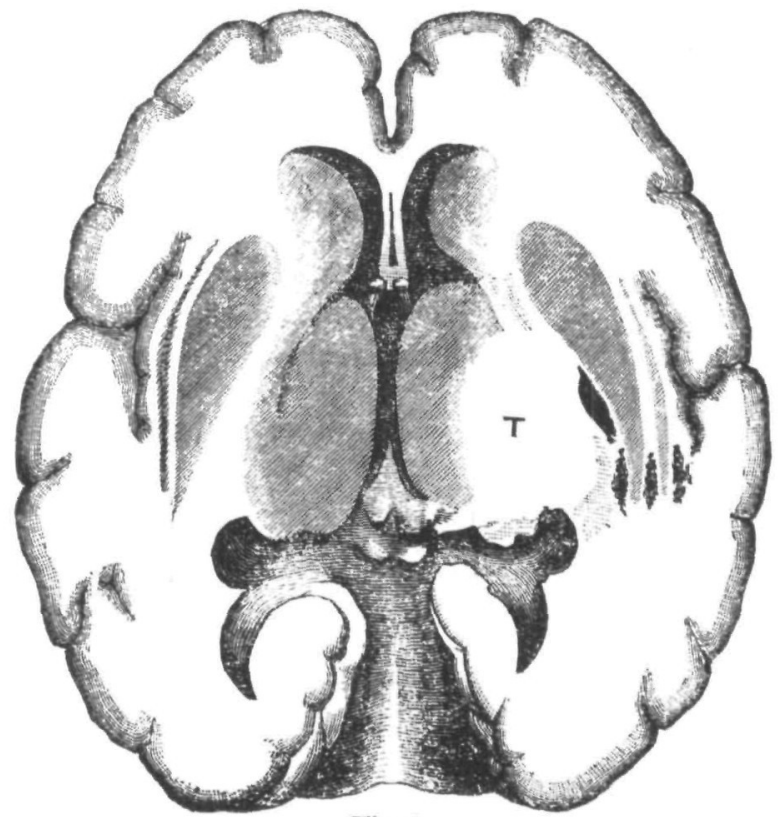

Fig. 1.

The right cerebral hemisphere appeared on superficial examination to be slightly more prominent than the opposite hemisphere, but there was no perceptible flattening of its convolutions. On transverse section of the brain there was found a tumour, diffuse in its distribution and in no way circumscribed or encapsuled, hence the determination of its exact limit was impossible. The main mass of the tumour, however, was situated in the posterior part of the internal capsule, extending from this as a centre to the optic thalamus, the lenticular nucleus, and the anterior of the corpora quadrigemina of the right side; all of which were infiltrated with new growth, and felt somewhat denser than normal. The anterior corp. quadrigem. was distinctly enlarged. The optic thalamus and lenticular nucleus were partly replaced by tumour-masses, partly simply pushed aside, so that their distal margins were more unduly separated than those of the corresponding opposite bodies (see fig. 1). On examining the base of the brain, the right optic tract, just where it crosses the crus, and where itself becomes hidden by the gyrus hippocamp., was found flattened, and somewhat softer than the corresponding left tract. 
brain were firm and healthy, and here again the right hemisphere only was found affected.

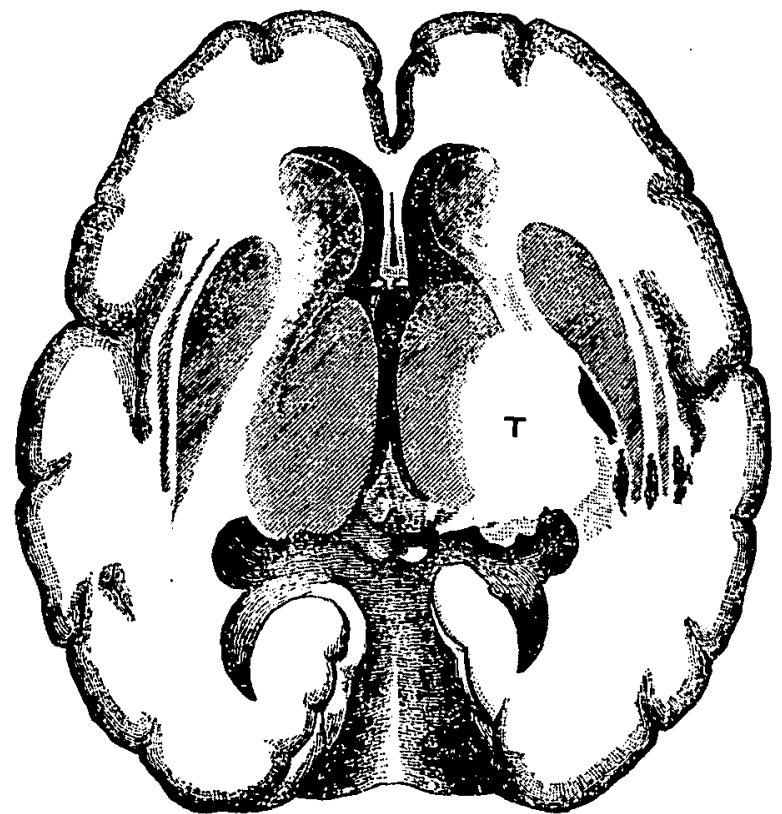

Fig. 1 .

The right cerebral hemisphere appeared on superficial examination to be slightly more prominent than the opposite hemisphere, but there was no perceptible flattening of its convolutions. On transverse section of the brain there was found a tumour, diffuse in its distribution and in no way circumscribed or encapsuled, hence the determination of its exact limit was impossible. The main mass of the tumour, however, was situated in the posterior part of the internal capsule, extending from this as a centre to the optic thalamus, the lenticular nucleus, and the anterior of the corpora quadrigemina of the right side; all of which were infiltrated with new growth, and felt somewhat denser than normal. The anterior corp. quadrigem. was distinctly enlarged. The optic thalamus and lenticular nucleus were partly replaced by tumour-masses, partly simply pushed aside, so that their distal margins were more unduly separated than those of the corresponding opposite bodies (see Fig. 1). On examining the base of the brain, the right optic tract, just where it crosses the crus, and where itself becomes hidden by the gyrus hippocamp., was found flattened, and somewhat softer than the corresponding left tract. 
The tumour was not, however, solid throughout. There was an irregular carity in its interior, which was opened by the last incision made to expose the tumour, and it appears in the sketch as an oval opening to the inner side of the lenticular nucleus near the posterior end of the latter structure, and involving also the posterior extremity of the claustrum; the substance of the brain was softened and presented a loose reticular appearance.

Microscopic sections of the tumour showed it to be of 8 sarcomatous nature. It consisted chiefly of round cells, with a reticulum of fine fibrillø, a few spindle cells, numerous blood-spaces, and embryonic blood-vessels.

The medulla and spinal cord, examined after hardening, showed the characteristic descending scleroses. I have recently again examined the sections of the cord, with the view of finding. the solerosed patch seen by Gowers in a case where there was anesthesia, and which is situated anterior to the lateral pyramidal tract, but $I$ found in this case no sclerosis on the spot indicated.

The symptoms observed during life are, as will at once be evident, satisfactorily explained by the situation of the tumour found in the brain. The tumour chiefly and primarily ocoupying the posterior part of the internal capsule explains the hemianæsthesia. The paresis and involuntary contractions observed during the first course of the disease are chiefly due, most likely, to an irritation of the motor fibres in the anterior part of the internal capsule, from the growth and extension of the tumour anteriorly. This state of irritation gave place to a state of paralysis, and hence we notice, during the fater progress of the case, the disappearance of the involuntary movement, and the increase of the paralysis of the left side.

As for the hemianopsia, this can be acconted for in more than one way. We have noticed that the right optic tract was softened and flattened; though microscopically examined, it presented no decided changes. This would, perhaps, be enough to account for the hemianopsia; though we know, on the other hand, that cerebral nerves will often, by slow pressure, become compressed, without, however, becoming impaired in their function. The thalamus opticus, again, was found affected to a very great extent; and this, especially when considered with the second case to be described, and with some recent cases recorded, ${ }^{1}$ might in itself be sufficient to account for the hemianopsia. Lastly, the right anterior ant. corp. quadrigem. was found enlarged and infiltrated

1 (Pflüger, ' Beriaht der Berner Augenblick,' 1818; Romy, Nothnigel, Topieche Diag., do, p. 281. Hughlingw-Jackson and Gowers, Ophthalm. Hosp. Rep., vol. viii, p. 930.) 
with new growth, and its connection with the optic tract is sufficiently well known. While thus the case does not teach us much as regards the course of the optic nerres in the basal ganglia, it offers an important support to the theory which adrocates partial decussation of the optic nerves, and from this point of view deserves to be placed on record.

The second case I wish to put on record is one in which the lesion which produced the hemianopsia consisted of a small hæmorrhagic focus situated in the posterior portion of the thalamus opticus, without in any way affecting either the truct, the corp. geniculate, or the corp. quadrig. For the purposes of localisation, this case, therefore, is of great importance.

In describing the history of the case and post-mortem appearances $I$ can be very brief.

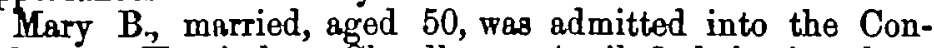
valescent Hospital at Cheadle on April 2nd, having been transferred thither from the Manchester Infirmary, where she Lad been under the care of Dr. Simpson-suffering from Bright's disease and mitral stenosis. During her stay at the Infirmary she had some cdema and ascites, which, however, had entirely disappeared on her admission into the Convalescent Hospital. On the morning of April 16th she had an apoplectic attack, ushered in by loss of consciousness; and when this had passed away, it was found that the patient had some amount of aphasia, which was, however, but transient, and left hemiplegio. Two days after the attack I saw the patient, in conjunction with Dr. Grant, the resident Medical Officer at Cheadle, and noticed the following conditions. The patient has left hemiplegia, complete as far as the arm and leg are concerned, the face is but little affected. She complaing of numbness in her left side and the sensibility seems slightly diminished on that side; her intelligence is clear, her speech but little affected. Occasionally she cannot find the exact word she wishes to express, but otherwise speech is unaltered. She complains of not being able to see well, and on examination it is found that she has left hemianopsia, the hemianopsia in each eye not reaching quite up to the point of fixation, but coming very near to it. The line limiting the hemianopsia is almost vertical, and the loss of vision within the area of hemianopsia absolute. The central vision of the patient is fairly normal, the fundus of the eye normal, the pupils are equal and react well to the light. There is no affection of any other of the cerebral nerves. The other special senses are normal.

The tendon reflexes on the paralysed side are slightly increased. There is no paralysis of either bladder or rectum. The area of cardiac dulness is increased, and over the apex a distinct systolic blowing murmur is beard, very limited in 
extent; the second aortic sound is much accentuated. The urinary secretion is profuse, and contains albumen and granular casts. The temperature of the body since the attack has been above the normal, showing evening exacerbations.

I saw the patient again on the 23rd of April, and found her in almost the same condition as on the previous visit, except for the hemiplegia, which was now less marked, the patient being able to move her hand and forearm slightly. The hemianopsia had remained in the same state. The patient complained of neither headache nor giddiness.

She remained in this state till April 29, when she became somewhat suddeuly drowsy, then comatose, and died the same day.

The post mortem was made on April 30 by Mr. Kaye, resident Clinical Clerk at Cheadle, who found the kidneys small and granular; the heart very much hypertrophied, especially the left ventricle; the mitral valve narrowed, but witbout any endocarditic deposits. The brain and its membrane showed externally normal relations, except the left lobe

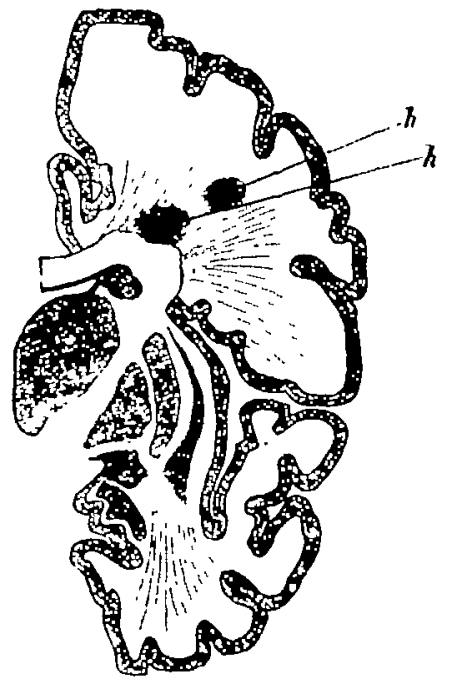

Fig. 2.

of the cerebellum, where a freshhømorrhage was found on the under surface of the lobe, just beneath the pia mater, forming a thin layer of about two lines in thickness and an inch in circumference. On making successive sections through the brain, the following lesions were found: 'Two small spots of hæmorrhage, $h . h$, Fig. 2, circular in ontline and of $\frac{1}{2}$ inch diameter in the 
centr. ovale of right hemisphere, corresponding to the ascending frontal convolution. (The accompanying drawing, Fig. 2, made by Mr. A. H. Young, shows theso lesions in M. Pitre's diagram.) A little behind these two hæmorrhages, corresponding nearly to the ascending parietal convolution, was another small hæmorrhage, smaller than the two just described, but again situated entirely in the centr. ovale, encroaching neither upon the cortex nor upon the basal ganglia. On making further sections through the brain, a small circular hæmorrhage, measuring about four lines in the larger transverse diameter and three lines in the vertical direction, was seen at the posterior and upper extremity of the right thalamus opticus, the part described as the pulvinar, not, however, reaching the upper surface of the thalamus, and therefore quite within its substance. The corpora quadrigemina, the corp. genicul., and the optic tract are found perfectly intact, nor did the rest of thalamus in the immediate neighbourhood of the hæmorrhage show any changes.

The diagnosis made during life was: " hæmorrhage into the right thelamus opticus, affecting the internal crpsule," and it was thought that there was only one hæmorrhagic focus.

The post-mortem examination showed that there were several spots of hæmorrhage, that the internal capsule was perfectly intact, and that the hemianæosthesia and the hemiplegia were due to separate hæmorrhages; for on comparing the symptoms during life with the lesions observed after death, I think there can be little doubt that the following is the correct view. The hemiplegia was due to the several hæmorrhages in the centrum ovale, for these are situated in that part of the white substance which contains the motor fibres radiating from the internal capsule to the motor area of the cortex (see Fig. 2). The hemianopsia was due to the hæmorrhage into the thalam. opticus. The hæmorrhage on the under surface of the left lobe of cerebellum, which was of more recent date then the other hæmorrhages, cannot well be connected with either the hemiplegia or the hemianopsia; it probably came on the last day of life, when the patient was noticed to become drowsy and comatose.

What makes this case especially interesting is the definite and well-circumscribed lesion in the thal. optic. with which the hemianopsia must be connected. Gowers has observed hemianopsia in many cases of cerebral hæmorrhage independently of the seat of lesion; in all these cases, however, the hemianopsia was temporary only, and soon passed away. In our case, on the other hand, the hemianopsia was permanent and, as regards its extent, constant.

Now it is admitted on all hands that fibres from the optio 
tract (chiefly of its external root) pass either directly or indirectly (through the external geniculate bodies, and according to some also through the anterior corp. quadrigem.) into the thalam. opticus, and thence to that portion of the cortex of the brain which forms the visual centre. Some other fibres, however, particularly those of the internal root, and the fibres described by Stilling as passing into a ganglion situated in the peduncle of the brain; do not traverse the thal. optic. If one may therefore draw conclusions from this case, it would seem that nearly all those fibres of the optic tract which are concerned in vision 'pass, after having undergone semidecussation in the chiasma, whatever their connection with the corp. quadrig. and corp. genicul. may be, almost in their entirety through the thal. optic. on their way to the cortical visual centre.

Looking over the literature of the subject, I find that there are a few cases on record in which lesions of the thalamus opticus were associated with hemianopsia ; in most, if not all, the lesions were more extensive, and implicated neighbouring parts.

In Pooley's case, ${ }^{1}$ where there was right paresis, right hemianæsthesia and right hemianopsia, a tumour was found in the occipital lobe reaching to the cortex; the thalamus opticus was found softened.

Baumgarten ${ }^{2}$ describes a case of left hemianopsia coming on suddenly in a patient affected with Bright's disease. Death ensued after several months. An old apoplectic cyst was found in the right occipital lobe and thalam. opticus.

The only other point I wish to draw attention to in our case is the condition of the pupil. This was found to react well to light, which would be quite in accordance with the view held by many that the centre for the reflex movements of the iris is situated neither in the cortex nor in the thalam. opticus, but most probably in the anterior corp. quadrigemina. I mention this, as it is important from a diagnostic point of view in distinguishing hemianopsia prodnced by a cortex lesion from hemianopsia produced by lesions of the optic tract, or of the ganglia situated in front of this reflex centre. 